\title{
RESENHA
}

\section{BRAGA JR, Amaro Xavier; SILVA, Valéria Fernandes da (Orgs.) Representações do Feminino nas Histórias em Quadrinhos. Maceió: Edufal, 2015. 330 p.}

\author{
MAYCON ANDRÉ ZANIN \\ UNIVERSIDADE ESTADUAL DO CENTRO-OESTE \\ (UNICENTRO-PR)
}

Este livro, lançado em 2015, é uma coletânea de artigos de pesquisadoras(es) brasileiras(os) que analisam como as questões de gêneros estão sendo representadas nos quadrinhos. Concentra-se na análise da representação dos papeis femininos nas histórias em quadrinhos desde 0 comics estadunidenses, passando pelos mangás japoneses (shonen e shojo) chegando às publicações undergrounds, tiras e biografias.

O livro apresenta 16 artigos, fruto do trabalho de 18 pesquisadoras(es) e está dividido em quatro partes definidas pela estética dos quadrinhos, sendo elas: quadrinhos infantis, de super-heróis/comics estadunidenses, mangás japoneses e undergrounds, tiras e biografias.

A primeira parte da obra denominada "quadrinhos infantis" apresenta os textos de quatro pesquisadoras, são elas: Marta Regina Paulo da Silva, Denise Castilhos de Araujo, Andréia Cristina Silva e Juliane Di Paula Queiroz Odinino.

Marta apresenta o texto "Mas só se For no Campo de Menina": Infância, Histórias em Quadrinhos e Relações de Gênero na Educação Infantil, resultado de parte da sua tese de doutorado; neste artigo, a autora analisa a partir das histórias da Turma da Mônica a relação entre infância, relações de gênero e histórias em quadrinhos e como as crianças "consomem" esses produtos. Segundo ela, o importante é saber como meninos e meninas pequenos(as) apropriam-se das HQs e nelas as questões referentes à relação de gênero e 0 que produzem a partir destas narrativas.

Denise Castilhos de Araujo discute os "Papéis Femininos em Mafalda", refletindo sobre os diferentes papéis das mulheres argentinas da década de 1960, que são muito atuais na nossa sociedade, a partir da produção do desenhista argentino Joaquim Salvador Lavado, mais conhecido como Quino. Mafalda, uma personagem com idade pré-escolar, é apresentada como questionadora dos conflitos sociais, políticos, culturais mundiais e da Argentina, vivenciando no seu dia a dia as preocupações dos seus leitores e da sociedade em geral. Segundo ela, a produção do autor analisado,soube demonstrar "a busca de igualdade entre os indivíduos,... a trajetória feminina na defesa de seus direitos". 
Em seu texto "Ethos feminino nos quadrinhos infantis: 'aniversário da Mônica ou festa do Mônico?'", Andréia Cristina Silva, analisa a inversão dos papéis femininos e masculinos dos personagens da Turma da Mônica na festa de aniversário da Mônica, destacando como o ethos e a representação de si no discurso ganha importância na narração das histórias em quadrinho. E como essas "imagens podem facilitar ou dificultar a aceitação do discurso, e ocorre constantemente no nosso dia a dia em qualquer ato comunicativo".

Juliane Di Paula Queiroz Odinino, no texto "Princesas, Heroínas ou SuperPoderosas? Agência e representação das personagens femininas infantis dos quadrinhos ao desenho animado", a autora analisa as transformações das personagens femininas nos quadrinhos e nas animações destinadas ao público infantil, a partir do seu amplo alcance, tem-se um grande número de expectadores/consumidores.

A segunda parte do livro reúne os textos de Natania Nogueira, Nildo Silva Viana e Gelson Weschenfelder, as reflexões dos autores partem dos comics estadunidenses, para discutir a constituição da super-heroínas, o contexto histórico, a releitura das personagens no passar do tempo.

No texto "II Guerra Mundial e as 'Super-Mulheres': o Surgimento das Super-Heroínas nos Estados Unidos da Década de 1940" "Natania Nogueira discute o papel das personagens femininas nas histórias em quadrinhos e as suas transformações no pós-guerra.

Nildo Silva Viana discute o "Inconsciente coletivo feminino e valores contraditórios na Mulher-Maravilha" procurando identificar os valores e concepções presentes nas histórias da Mulher-maravilha e a manifestação do inconsciente coletivo feminino nesse universo, analisando a personagem a partir os conceitos de: valores, axiologia, axionomia, ideologema, teorema e inconsciente coletivo.

Gelson Weschenfelder, no texto "As Super-Heroínas como instrumento de gênero nas histórias em quadrinhos", analisa a representação feminina nas histórias em quadrinhos e o papel das personagens Mulher-maravilha, da editora DC; Tempestade e Jean Grey dos X-men, da editora Marvel, num contexto da libertação feminina.

A terceira parte do livro traz os textos de Sonia Bibe Luyten, Taís Marie Ueta e Yuji Gushiken, e Valéria Fernandes da Silva, os autores analisam a produção dos mangás japoneses, principalmente o "shoujo mangá", que é destinado ao público feminino. $O$ papel que as personagens representam e a idealização do feminino são assuntos que os autores discutem neste bloco.

No texto "A produção e retratação da mulher nos quadrinhos ocidentais e no mangá: Romantismo e Erotismo", de Sonia Bibe Luytentem como objetivo verificar a representação da mulher nos quadrinhos orientais e ocidentais, num contexto Brasil-Japão. A autora também analisa a participação das mulheres como produtoras/desenhistas de histórias em quadrinhos ou charges publicadas nos diferentes períodos da história.

Taís Marie Ueta e Yuji Gushiken problematizam "O Feminino na produção de Mangás", apresentam em seu texto a contextualização da criação e o enredo dos mais variados mangás e diferentes estilos, publicados no Japão e 
traduzidos em diversos países. Problematizando o papel das personagens na representação do ideal feminino nessas obras.

A historiadora Valéria Fernandes da Silva, em seu texto "A GarotaPríncipe nos shoujo mangá: discutindo as fronteiras de gênero", analisa a construção do modelo garota-príncipe, nas obras "A princesa e o cavaleiro", de 1953; "A rosa de Versalhes", 1972-1974; "A espada de Paros", 1986-1987, e "A garota revolucionária", 1996-1997, em que as protagonistas apresentam tanto atributos femininos quanto masculinos.

Otávia Alves Cé, no texto "Elas para Eles e Elas para Elas: diferenças e semelhanças na representação de personagens femininas nos mangás shonen e shojo", a autora destaca a divulgação e da facilitação do acesso aos mangás e animes japoneses, em que muitas crianças e jovens ocidentais tiveram conhecimento e incorporaram elementos presentes no cotidiano japonês. Apresenta uma conceitualização da estética e estilo da narrativa dos mangás e a definição dos estilos shojo e shonen. Além da análise sobre a caracterização de diferentes personagens nos estilos shojo e shonen.

A quarta e última parte da obra "Undergrounds, tiras e biografias", reúne os textos de Maria Adriana Nogueira e Daiany Ferreira Dantas, Thayse Madella, Luciana Zamprogne, Alba Valéria Tinoco Alves Silva e Karine Freitas Sousa. Coincidentemente, temos dois trabalhos sobre a mesma obra "Retalhos" (2010), demonstrando como as análises sobre as histórias em quadrinho podem ser fecundas.

Maria Adriana Nogueira e Daiany Ferreira Dantas discutem no texto "Feminino, intimidade e subversão em Bordados, de Marjane" a partir dos conceitos de resistência aos dispositivos de sexualidade presentes no pensamento de Michel Foucault (1988), analisam a obra Bordados da iraniana Marjane Satrapi procurando compreender a identidade feminina das mulheres islâmicas, a partir de conceitos como o de construção de identidade e construção do feminino.

No texto "Casamento, virgindade e falocentrismo: a subversão de tradições patriarcais no romance gráfico 'Bordados', de Marjane Satrapi", Thayse Madella analisa as representações gráficas dos depoimentos das personagens, procurando mostrar as lutas diárias dessas mulheres para subverter no sistema patriarcal do Irã, as regras que as oprimem.

O texto de Luciana Zamprogne, "Como estranhos podem encontrar o paraíso: contra-discursos, ideologias e representações do feminino na sociedade contemporânea", a autora apresenta a possibilidade de analisar a sociedade a partir da cultura pop, ressaltando que ela é produto de um contexto histórico, carregado de estruturas simbólicas, subjetividades e racionalidades individuas ou coletivas.

Alba Valéria Tinoco Alves Silva, analisa "O Traço de 3 mulheres nas tiras em quadrinhos de humor", centralizando suas reflexões nas produções de Cecilia Whitaker de Azevedo Alves Pinto - Ciça, Pryscilla Vieira e Cibele Santos. A autora expõe o baixo número de mulheres na produção dos quadrinhos de humor e procura responder se existem divergências entre homens e mulheres na representação do humor. 
O texto de encerramento "As (Sub) subalternas mulheres em Scott Adams", de Karine Freitas Sousa procura analisar, a partir das histórias em quadrinhos fragmentos das violências simbólicas de gênero sofridas pelas mulheres profissionais presentes nessas histórias.

Concluindo, a obra Representações do Feminino nas Histórias em Quadrinhos, conseguiu reunir uma expressiva amostra de trabalhos desenvolvidos a partir da problematização da questão de gênero apresentadas nas histórias em quadrinhos. Os autores procuram demonstrar a representação dos papéis femininos nos mais diferentes formatos e estilos das histórias em quadrinhos, criticando a desigualdade entre a representação do masculino e do feminino nesse universo. Dessa forma, acredito que a intenção desse trabalho é a de demonstrar aos mais variados leitores como as HQs podem ser utilizadas como fonte para as pesquisas, nas diferentes áreas do conhecimento, proporcionando reflexões e discussões sobre as diferentes representações do mundo presentes em seus enredos.

\section{Sobre o autor}

Maycon André Zanin é mestrando no Programa de Pós-Graduação em História do Unicentro (Universidade Estadual do Centro-Oeste - Paraná). E-mail: maycon zanin@yahoo.com.br.

Recebido em 19 de outubro de 2015.

Aprovado em 15 de março de 2016. 